\title{
LA REFORMA AGRARIA Y LA AGRICULTURA MEXICANA: INTENTO DE SISTEMATIZACION*
}

\author{
Por Horacio CIAFARDINI
}

\section{INTRODUCCION}

La reforma agraria mexicana es por lo general poco conocida en América Latina. La "mística" de la revolución mexicana, aunque con características distintas que en el propio México, flota sobre ideas vagas en toda Latinoamérica. Decía un autor en un libro reciente: "Algunos científicos sociales estadunidenses, poco a poco, se transforman en ideólogos de una visión norteamericana de América Latina. Por eso la revolución mexicana ha sido idealizada por algunos de esos científicos sociales. Por tal motivo, algunas realizaciones resultantes del proceso revolucionario mexicano han sido consideradas como ejemplos susceptibles de ser transferidos a otros países latinoamericanos. Sin embargo, se nota que se pretende generalizar los resultados del proceso revolucionario y no el propio proceso revolucionario." 1

Es propósito de este trabajo tratar de presentar sistemáticamente el proceso agrario de la Revolución, intentando luego sistematizar los datos de los censos de 1960 a manera de poner de manifiesto, en lo posible, la estructura capitalista, aunque moderna, resultante. Cabe hacer notar que, dada la vaguedad de la información disponible, quedó prácticamente excluida del análisis la producción ganadera.

* Versión abreviada.

1 octavio Iani, Imperialismo y Cultura de la violencia en América Latina, Editorial Siglo xxr. D. 27. 


\section{RESENA HISTORICA}

\subsection{La reforma agraria}

El problema agrario tenía características tan explosivas que la propia administración porfirista confecciono un proyecto de reforma agraria antes del inicio de la Revolución (cuyos luchadores más radicales serían a menudo, como Zapata, agricultores desposeídos en la misma época y manera que los poseedores de tierras comunales).

La revolución de 1910 sin embargo, sólo después de varios cambios de gobierno impuestos por renovadas luchas, llegó a trascender en los hechos el lema inicial de Madero ("sufragio efectivo y no reelección") hacía cierta concreción del ideal revolucionario campesino de Zapata ("tierra y libertad"). La reforma agraria sólo es consagrada formalmente en 1917 bajo Carranza, quien afrontaba todavía la resistencia de los campesinos morelenses de Zapata (éste sería, sin embargo, asesinado en una emboscada del ejército en 1919) y el reparto de tierras sólo comienza a hacerse significativo en 1921, bajo la administración presidida por Alvaro Obregón a quien, con bastante exageración, un intelectual zapatista llamó "ejecutor del pensamiento de Emiliano Zapata"."

\section{RITMO DE DISTRIBUCION DE TIERRAS Y TAMANTO DE} LAS PARCELAS

\begin{tabular}{|c|c|c|c|c|}
\hline Periodo & $\begin{array}{c}\text { Administración } \\
\text { presidencial }\end{array}$ & $\begin{array}{c}\text { Superficie } \\
\text { media anual } \\
\text { distribuida } \\
\text { (miles de Has.) }\end{array}$ & $\begin{array}{c}\text { Número } \\
\text { medio } \\
\text { anual de } \\
\text { beneficiarios } \\
\text { (miles) }\end{array}$ & $\begin{array}{c}\text { Superficie } \\
\text { media } \\
\text { por benefi- } \\
\text { ciario (Has.) }\end{array}$ \\
\hline & $\begin{array}{l}\text { Carranza } \\
\text { De la Huerta }\end{array}$ & 71 & & \\
\hline $1921-24$ & Obregón & 389 & 40 & 9.6 \\
\hline $1925-28$ & Calles & 761 & 75 & 10.2 \\
\hline 1929 & Portes Gil & 1750 & 126 & 13.8 \\
\hline $1930-32$ & Ortiz Rubio & 485 & $?$ & $?$ \\
\hline $1933-34$ & Rodriguez & 960 & 79 & 12.2 \\
\hline $1935-40$ & Cárdenas & 2935 & 129 & 22.5 \\
\hline $1941-46$ & Ávila Camacho & 559 & 19 & 29.0 \\
\hline $1947-52$ & Alemán & 669 & 12 & 54.0 \\
\hline $1953-58$ & Ruiz Cortines & 533 & 42 & 13.0 \\
\hline
\end{tabular}

FUENTE: SILVA HERzoG J. El agrarismo mexicano..., pp. 280, 322, 364, $405,452,489$ y 535

JeSús SILvA HeRzoo, El agrarismo mexicano y la reforma agraria. Exión y crítica. Fondo de Cultura Económica, 1959, p. 309.
Tomando como hito la administración Cárdenas la tendencia es, en el período anterior, al aceleramiento en cuanto a la extensión total distribuida, con aumento del número de beneficiarios y de la superficie media de las parcelas. Luego se frena fuertemente el ritmo aunque el tamaño medio de las parcelas (ahora predominantemente tierras fiscales, de peor calidad) continúa aúmentando.

Un autor, a partir del estudio del pueblo de Tepoztlán, constata que "a partir de 1938 podía esperarse que los jóvenes reclamasen en número creciente una participación en el derecho que les otorgaba la mera nacionalidad; pero se trataba precisamente de eso, de un derecho otorgado por la mera nacionalidad. Lo mismo ocurría en todo México, incluyendo las municipalidades lindantes con Tepoztlán. Así es que había competencia entre cantidades crecientes de aldeanos por cantidades decrecientes de la vital mercancía, la tierra cultivable."3

A partir de la década de 1950 se advierte una clara tendencia a dotar a un número mucho mayor de personas de extensiones mucho menores y a menudo de baja calidad; en relación, indudablemente, con un crecimiento demográfico de los más rápidos de la tierra; esta tendencia agudiza tensiones. En los estados de Hidalgo, Querétaro, Guanajuato, perviven intactos latifundios de hasta 20 mil has., pero si se distribuyesen todas las tierras hoy consideradas afectables, sólo bastarían para la décima parte, más o menos, de los que podrían aspirar a obtener parcelas.

En el proceso de reforma agraria aparecen mezclados y alternados el proyecto liberal-burgués basado en la "pequeña propiedad" y el proyecto campesino-revolucionario, utópico como objetivo aislado, de la reconstrucción sobre bases modernas del ejido indígena, correspondiente a la línea de Zapata y Cárdenas. Correlativamente, el ejido fue concebido de dos maneras: como dotado de una mera función auxiliar en una agricultura capitalista (sea el "ejido-pegujal", como complemento del salario, sea el ejido-parvifundio de subsistencia, migaja de tierra destinada simplemente a pacificar el campo hasta cierto punto) y como forma de la producción agraria, con carácter colectivista de cooperativa de producción.

En los años 20, Covarrubias sostenía lúcidamente que "no es de suponerse una posible competencia comercial entre los poseedores de ejidos y los dueños de haciendas. Subsistiendo la explotación capi-

${ }^{3}$ PETER coy, "A Watershed in Mexican Rural History: Some Tought on the Reconciliation of Conflicting Interpretations", Journal of Latin American Sturdies, Vol. 3, Part I. May 1971, p. 50. 
talista de las haciendas, los pueblos indigenas tienen que seguir siendo, con ejidos o sin ejidos, pueblos de peones, y únicamente se conseguirá con la abundancia de tierras comunales aligerar la carga de los hacendados quienes, cuando tengan pueblos vecinos con ejidos, podrán disponer de los peones suplementarios que necesitan para las siembras y para las cosechas, sin necesidad de tenerlos que mantener todo el año ocupados en trabajos no indispensables ... en las épocas en que las faenas agrícolas son menos activas".

El presidente Cárdenas, en un discurso pronunciado en 1936 en relación con la expropiación de ricas tierras de La Laguna, decía evocando el mismo problema desde un punto de vista opuesto: "Pudo haber habido, en alguna época temprana de la Revolución, quienes consideraran al ejido como mero suplemento del jornal ... pero esto nada influye en los deberes presentes de la autoridad. Que grupos campesinos llegaran a poseer pequeños lotes de tierra, verdaderos «pegujales» sin aperos, sin crédito, sin organización, era fruto bien raquítico de tamaño sacrificio en la lucha. $Y$ esto sin contar con que el ejido así entendido habría acabado por ofrecer un recurso más para que el hacendado pudiera disminuir los jornales - de suyo envilecidos - sabiendo que el trabajador contaba con un arbitrio adicional para subsistir". ${ }^{5}$

En realidad, sólo la presidencia de Cárdenas registra un impulso importante para la creación de ejidos de explotación colectiva; de 700 a 800 cooperativas de producción fueron puestas en marcha en la segunda mitad de la década de 1930 en La Laguna, en Yucatán, en el Río Yaqui, en Los Mochis, en Michoacán y son, por lo demás, los ejidos mejor dotados de tierras de regadío. ${ }^{6}$ Pero, a partir de 1940, la corriente de profundización de la revolución en cuanto a la cuestión agraria se invierte: en realidad, se da por terminada la Revolución. El momento decisivo puede situarse en 1942, año de los acuerdos Roosevelt-Ávila Camacho que cierran el conflicto con los Estados Unidos desencadenado por la nacionalización del petróleo y abren una válvula de escape a los problernas sociales del campo mexicano al dar acceso al mercado norteamericano a muchos productos agrícolas mexicanos y a la emigración temporaria de los braceros.

Los ejidos no pudieron por menos de tener, en definitiva, principalmente el destino que las vaticinaba Covarrubias y rechazaba

4 JesÚs sILVA HERzOG, op. cit., pp. 294-356-357.

5 lbid., p. 409 .

a Documentation Franchase. "Mexique 1969. La reforme agraire a un tournant", serie Problemes d'Amérique Latine, No. 15, Paris 1970, p. 48.
Cárdenas. En 1960 se evaluaba en un 3\% solamente de las tierras ejidales la porción de éstas que se explotaba colectivamente; hay coincidencia entre todos los autores serios en que "sólo en contados casos los ejidos tienen ese sentido". " En 1940 el 15\% de los ejidatarios declararon que trabajaban como jornaleros, el $19 \%$ en 1950, el $25 \%$ en 1960, y su número se duplicó en veinte años.

\subsection{La "reforma agrícola"}

Al frenarse la reforma agraria a partir de la década de 1940, comienza un desarrollo importante de la empresa capitalista agraria técnicamente moderna, poniéndose el énfasis en la expresión "reforma agrícola" (técnica) : esencialmente aparece en el crecimiento de la infraestructura, impulsada y solventada en lo fundamental por el estado, y en la utilización de insumos industriales en las explotaciones.

La historia reciente de la irrigación en México comienza en 1926, con la ley que declara empresa de servicio público la irrigación de las tierras de empresas privadas. Se llega a 1940 con 271000 has. de regadío solamente. Pero en 1950, las sumas destinadas por el estado a la promoción de la agricultura representaban ya el $1.24 \%$ del presupuesto nacional y el $3.25 \%$ del presupuesto económico", y en 1950 ya el $2.62 \%$ y el $5.93 \%$ respectivamente. ${ }^{9}$ Según otro autor, las inversiones de desarrollo básico en la agricultura habían representado el $10.7 \%$ de las inversiones públicas en 1959-61 y el $17.8 \%$ de las cifras planificadas para 1962-64.10 En 1967-68 el rubro irrigación absorbía cerca del $10 \%$ de las inversiones públicas federales y debía llegar, según el presupuesto, al $8.3 \%$ del total de gastos del gobierno federal en 1969 (El mercado de valores, 9/9/68). La superficie irrigada, recuperada o mejorada alcanzó en los años 1947-52 una media anual equivalente al doble, y en $1952-58$ al triple, de la del período 1926-47. ${ }^{11}$ No fue el privilegio de la "aristocracia de la tierra" de que hablaban el general Calles ${ }^{12}$ y cuya liquidación éste no veía en pers-

7 rodolfo stavenhagen y otros, Neolatifundismo y explotación. De Emiliano Zapata a Anderson Clayton \& Co., Editorial Nuestro Tiempo, 1968, p. 47.

8 DOCUMENTATION FRANĢase, op. cit., p. 43.

HOWARD CLINE, Mexico, revolution to evolution, Oxford University Press, 1962, p. 347.

10 MIGUel wronczex, "El caso mexicano", en Planificación para el desarrollo, editado por H. E. Hagen, FCE, México, 1964.

11 HOWARD OLINE, op. cit., p. 339.

12 En 1925, al promover la ley de irrigación, el presidente Calles formulaba la posibilidad de que los recursos de regadío se convirtieran en privilegio 
pectiva en el curso de la reforma agraria, pero sí el de los "pequeños propietarios" resultantes, justamente, de la reforma. Algo más de la mitad de la tierra irrigada hasta 1940 correspondía a ejidos, pero ya en 1951 esta proporción estaba por debajo del 411\%, según censos, pese a que la superficie de los ejidos aumentó después de 1940 como porcentaje de la superficie total de las explotaciones. Según datos de la Secretaría de Recursos Hidráulicos, en 1958 había 15.104 ejidatarios con algo más de 10 has. de regadío en promedio, contra 28657 propietarios privados por encima de ese umbral (con un promedio mucho mayor).

El transporte es otro elemento de infraestructura solventado por el estado que ha venido a favorecer a prósperos "colonos" o "pioneros" necesitados de dar salida a la producción de zonas agrícolas nuevas. El grado de mecanización de las tareas agrícolas para el conjunto del sector pasaba de $11 \%$ en la década de $1950 \%^{13}$ según cifras oficiales la producción de tractores habría aumentado en un $60 \%$ en 1967-68, las importaciones de tractores casi en la misma proporción y las de insecticidas, parasiticidas y fumigantes en un $42 \%$ (Comercio Exterior, marzo de 1969); el consumo de abonos se había multiplicado prácticamente por 18 en la década de $1950^{14}$ y la producción de abonos se había multiplicado por 63 entre 1950 y 1970 . En cuanto a la producción de semilla mejorada y seleccionada, lanzada en 1948 por el gobierno, alcanzaba ya a comienzos de la década de 1960 para sembrar toda la superficie destinada al algodón y porciones crecientes de las dedicadas a trigo y maíz. ${ }^{15}$

\subsection{Crecimiento reciente del sector agropecuario}

El crecimiento global de la economía de México presenta un ritmo superior al de la mayoría de las economías latinoamericanas, lo de una minoría: "Si las obras de regadío que se construyen sólo pudieran
servir para estabilizar el latifundio, era preferible que no se llevaran a cabo con recursos del gobierno, a pesar de que se alcanzara el fin puramente utilitario del aumento de la producción, ya que entonces el estado vendría a ser el auxiliar de unos cuantos privilegiados, y las obras de regadío sólo servirían para consolidar la dominación de una aristocracia de la tierra." (Citado en SILVA HeRzoG, El agrarismo mexicano..., p. 326.)

13 ANTONIO GARcín, "El problema empresarial y la reforma agraria en América Latina", El Trimestre Económico, No. 134, México, Junio 1967.

14 ELIAL VARGas TORRES, "El producto y la productividad agrícolas", El Trimestre Económico, México, abril-junio 1965, p. 259.

15 Ibid., pp. 259-260. Los pequeños productores, al parecer, sufrieron fraudes considerables en la venta de semillas $v$ abonos pasados e. ineficaces. que está en relación con un proceso de inversión estatal y privada extranjera cuyas características no es posible analizar aquí. El consumo de alimentos en las ciudades acompaña este incremento del producto. En 1957 se alcanzó más o menos definitivamente el autoabastecimiento de trigo. Los rendimientos casi se triplicaron en 20 años pese a que la mayoría de los sembradíos de este cereal ya estaban irrigados al comienzo de ese período (1943-63). Los $2 / 3$ de la producción triguera se alcanzan ahora en las regiones "capitalistas" del Pacífico Norte y del Norte, mientras que en 1943 la misma proporción venía del Norte y de la región "campesina" del Centro. ${ }^{16}$

Entre $1945-47$ y 1958-60, la tasa media anual de crecimiento de la producción agropecuaria fue de $7.1 \%$ contra $3 \%$ de la población. El índice de la producción agrícola, con base 1934-38-100, llegó en 1965 a 324, contra 227 en Colombia, 196 en Brasil, 133 en Argentina. ${ }^{17}$ Entre 1948 y 1957 el producto agrícola llegó a crecer más rápidamente que el producto total. En 1948-52, en pleno auge de la "reforma agrícola", el incremento absoluto del producto por agricultor representó cerca de $1 / 3$ del incremento absoluto del producto por persona activa en toda la economía, la relación más favorable en 30 años.

\section{EL ESTADO ACTUAL}

Como se desprende de lo anterior, la reforma agraria y la "reformá agrícola" no fueron, en México, dos aspectos complementarios de un proceso democrático que hubiese quebrado el capitalismo en el campo. Ello sólo hubiera sido concebible como parte de un programa de transformación revolucionaria de toda la sociedad. El "fra-

Por lo demás, los miembros de la misión encargada de contribuir con investigaciones azgronómicas por cuenta de la fundación Rockefeller han reconocido que: "Los híbridos se habían producido en un plazo notablemente breve, pero desgraciadamente sólo los agricultores progresistas, relativamente poco numerosos, estaban dispuestos a servirse de ellos. La producción y el mantenimiento de las semillas requerían expertos y las semillas eran demasiado costosas para la mayor parte de los agricultores... Los híbridos no han llegado todavía a los pequeños productores mexicanos en cantidades importantes..." (stakMan y otros, Campaign against hunger, Harvard University Press 1967, pp. 70-71).

16 STAKMAN y otros, op cit., pp. 3-7 y 91

17 EDMundo FLoRes, "Cómo funciona el sector agropecuario de México", Comercio Exterior, septiembre, 1967. 
caso" de la revolución mexicana $\mathbf{1}^{18} \mathbf{o}$, mejor dicho, del proyecto de sus participantes más radicales, iba implícito en el carácter específicamente agrarista de sus reivindicaciones. La reforma agraria, en la medida en que tuvo efectivamente lugar, consistió centralmente en sucesivos repartos de tierra cuya función resulta ser históricamente la de asegurar, como válvula de escape, el mantenimiento en sordina de conflictos profundos y a la vez, en muchos casos, la estabilización de reservas de fuerza de trabajo estacional, etcétera. Al frenarse la reforma agraria cede paso, en forma sucesiva, a la "reforma agrícola".

El resultado no podía ser una agricultura basada en los ejidos colectivos que sólo Cárdenas impulsó desde el gobierno - a menos que la revolución se profundizase globalmente-, sino que tuvo que ser una agricultura basada en la empresa capitalista moderna rodeada de un campesinado pobre y un semi-proletariado numeroso, como lo ha reconocido póstumamente el propio Cárdenas. ${ }^{10}$

\subsection{La fuerza de trabajo}

Hace ya una década, los asalariados predominaban numéricamente en el seno de la población activa del campo. Según unos, los trabajadores sin tierra habían pasado de $48 \%$ a $531 \%$ de ésta entre

18 "Es cierto qùe México tiene índices económicos, sociales y políticos mucho más elevados que los de Colombia, Bolivia, Perú e incluso, en ciertos en ciertos casos, Brasil, ni qué decir de los países de América Central. Pero cuando se toman en cuenta las elevadas cifras de mortalidad, mortalidad infantil, analfabetismo, desnutrición, población dedicada a la agricultura, población trabajadora no organizada y población que no vota, así como el estado en que se encuentran actualmente las organizaciones laborales y el extraño significado de las elecciones políticas, muchos preguntan: ¿ No ha fracasado, realmente, la Revolución mexicana? ¿Fue para esto que murió un millón de personas?" (PABLo GonzÁlez casanova, "Méxiç: A semi-capitalist revolution" en Planning and Economic Development, I. Sachs PWN, Varsovia 1964.

19 "El retroceso y el relativo desorden prevalecientes en algunas de esas zonas (donde se dotaron ejidos colectivos - $\mathrm{HC}$ ) se deben a la falta de interés para impulsar el ejido colectivo. La consecuencia ha sido el innegable regreso, franco o subrepticio, de los terratenientes que, por la cuantía de los intereses que representan, se han podido posesionar otra vez de las tierras y las máquinas o influyen a través del crédito usurario en la producción y la comercialización de las cosechas, apropiándose de los rendimientos obtenidos con el esfuerzo de los campesinos..." (Lázaro cárdenas, "Un balance de la Revolución mexicana" (Testamento político) Suplemento de Comercio Exterior. octubre 1971 .
1950 y $1960 . .^{\text {Eo }}$ Según una encuesta del Banco de México, en 1963 representaban el $51 \%$ del total de familias, correspondiendo el resto a familias de empresarios pobres (37\%) y de empresarios ricos $(12 \%)$. El Centro de Investigaciones Agrarias estimaba a los trabajadores sin tierra en unos 3 millones en $1967 \mathrm{y}$, teniendo en cuenta la poca capacidad de absorción de fuerza de trabajo de la industria en los últimos tiempos y el ritmo acelerado de incremento de la población, existen estimaciones en el sentido de que llegarán a 5 millones hacia 1980 (Documentation Francaise, p. 44). Por lo demás, podría pensarse que una parte de la fuerza de trabajo que aparece en las estadísticas como "familiar no remunerada" sea, en realidad, también asalariada, como ha resultado ser en otros países.

Dentro de los ejidos se viene dando desde hace tiempo un proceso de descomposición o "diferenciación" social que introduce relaciones salariales entre ejidatarios, ${ }^{21}$ así como entre éstos y empresas exteriores al ejido. Según el ex presidente Cárdenas, "estimulados por las reformas contrarrevolucionarias introducidas en la Constitución y las leyes agrarias en el año de 1946, que ampliaron las dimensiones de la llamada pequeña propiedad agrícola y que otorgaron inafectabilidades improcedentes junto con el recurso de amparo que aprovechan los que más tierra tienen, los propietarios favorecidos se han dedicado a comprar o alquilar fraudulentamente terrenos ejidales, auténticas pequeñas propiedades y minifundios, extendiendo el sistema capitalista de explotación rural, con mano de obra ejidataria o de trabajadores aleatorios, y creando con ello un nuevo proletariado del campo que vive en el desamparo, sin la protección de las leyes

20 rodolifo Stavenhagen, "Social Aspects of Agrarian Structure in Mexico", reprinted from Social Research, Vol. 33, No. 3, 1966, p. 485.

21 Ya en 1937 se señalaba en ciertos estados que "la distinta calidad de los terrenos" había originado "una lamentable desigualdad entre los ejidatarios que estaba ya dando como resultado la explotación de los menos favorecidos por aquéllos a quienes les habían tocado las mejores parcelas, tanto por la fertilidad de la tierra como por la abundancia de agua para riego" (op. cit., p. 438).

Por otra parte "podía echarse mano de técnicas relativamente elaboradas. Por ejemplo: el otorgamiento de una parcela ejidal traía aparejado el derecho a un crédito del Banco Ejidal. Esta favorable franquicia, según el ingeniero Fabila, se usaba para adquirir un tractor que podía utilizarse en la tierra privada de un ejidatario emprendedor y también para prestar servicios a otros ejidatarios. Una persona en estas condiciones podía permitirse también operaciones de acaparamiento, usura, emplear trabajadores en su parcela a tasas de remuneración mínimas..." (PETER coY, op. cit., p. 55.). 
del trabajo, pues ni siquiera está organizado en sindicatos como los que existían cuando se empezó a aplicar la reforma agraria."22

\subsection{La tierra}

Como suele ocurrir, existen discrepancias entre los datos de los censos y los que aceptan estudiosos de la agricultura mexicana en cuanto a la distribución de la tierra. Esto se debe probablemente a la disimulación de propiedades mediante testaferros y a la metodología de relevamiento estadístico "por establecimiento" y no "por empresa". El ex presidente Portes Gil señalaba la frecuencia de tal disimulación, que permitía concentrar extensiones de tierra, especialmente irrigada, muy superiores todavía a los generosos topes establecidos en la reforma constitucional de 1946. Decía en 1953: “... debe evitarse que, a pretexto de pequeñas propiedades, toda una familia de 10 o 15 miembros $(\ldots)$ ocupen cada uno lotes de 100 has. que en total suman un verdadero latifundio de 3 o 5 mil has. $Y$ esto en superficies irrigadas por presas que el pueblo de México está pagando." 23

Las unidades muy grandes, según censos, cuyos recursos de tierras de regadío son poco importantes como porcentaje del total, resultan de consideración al tomarse en cuenta las cifras absolutas. Estas 13000 empresas (o, más bien, establecimientos) tienen en promedio no sólo más de 7000 has., sino cerca de 500 has. de labor y más de 45 has. de regadío.

Conviene señalar asimismo que la comparación de los censos de 1940 y de 1960 muestra un proceso de concentración que no afecta, al parecer, a las muy pequeñas explotaciones y parcelas ejidales (aunque allí la concentración se da por arrendamientos ilícitos que no pueden registrar las estadísticas). La superficie de labor de las unidades comprendidas entre 5 y 200 has. disminuye ligeramente, mientras que la de las más grandes aumenta tanto más sustancialmente cuanto mayor es la superficie unitaria.

\subsection{La producción agrícola}

Al considerar la distribución de esta variable, resulta interesante comenzar por una comparación de las dos categorias globales (demasiado globales) en que las estadísticas mexicanas presentan la mayor

22 LÁZARO CÁRDENAS, op. cit.

23 Jesús SILva herzoo, op. cit., p. 546. parte de los datos referentes al "sector privado": explotaciones mayores de 5 has, explotaciones menores de 5 has.

En primer término, llama la atención la existencia de explotaciones inferiores a 5 has. de superficie que superan en ciertos casos aun 2000 dólares de producción anual. Es más, la mitad de estas unidades (un centenar, aproximadamente) se encuentra en la región del Centro, aquélla más afectada por el minifundio y la superpoblación relativa. Se trata seguramente de unidades situadas junto al límite superior de la categoría, con tierra de buena calidad o aun irrigada íntegramente y dedicada a utilizaciones intensivas para el aprovisionamiento de comestibles a mercados urbanos contiguos. El fenómeno resulta a la vez interesante y marginal. En efecto, se comprueba por otro lado, que el grueso de las unidades inferiores a 5 has. de superficie presentan montos de producción muy bajos: más del $80 \%$ de las explotaciones del "sector privado" que no llegan a 400 dólares, y alrededor del $90 \%$ de las que no llegan a 80 dólares, tienen menos de 5 has. de superficie. El conjunto de las explotaciones de menos de 5 has. puede, con poco margen de error, hacerse entrar en el grupo de los minifundios.

\section{DISTRIBUCION DE LAS EXPLOTACIONES DEL "SECTOR PRIVADO" POR INTERVALOS DE VALOR DE LA PRODUCCION} AGRICOLA. 1960

\begin{tabular}{ccc}
\hline $\begin{array}{c}\text { Categorias (intervalos de } \\
\text { valor de la producción } \\
\text { agricola) }\end{array}$ & $\begin{array}{c}\text { Explotaciones de más } \\
\text { de } 5 \text { ha. de super- } \\
\text { (dicie }\end{array}$ & $\begin{array}{c}\text { Explotaciones de } \\
\text { menos de } 5 \text { ha. } \\
\text { de superficie }\end{array}$ \\
(número de explotaciones: porcentajes)
\end{tabular}

Nota: Se convirtieron los pesos mexicanos en dólares mediante la tasa media de cambio de 1960, según Anuarios Estadísticos.

fuente: IV Censos Agricola-ganadero y Ejidal 1960. Resumen General.

Considerando el "sector privado" en su conjunto, surge a simple vista que la producción agrícola se encuentra muy concentrada. Rigurosamente, esto se mide por el coeficiente de concentración que, calculado para esta distribución, arroja un resultado de 0.803 . 
No se pueden incorporar al cuadro las parcelas ejidales. Baste con indicar por el momento que, en promedio, se situarían en la categoría de 80-400 dólares de producción anual (eran 1.5 millones dotadas de tierra cultivada en 1960, y su producción agrícola ascendía a 5870 millones de pesos, o sean 468 millones de dólares).

El cálculo de los correspondientes coeficientes de concentración para las distribuciones de las tierras de cultivo, de la producción agrícola expresada en moneda y del monto de las ventas de productos agrícolas arroja resultados que permiten afirmar que las tres variables se han concentrado durante las décadas de 1940 y de 1950.

El cuadro siguiente - construido mediante la aplicación de ciertos supuestos indispensables para poder procesar la información censalpermite comparar la distribución de la producción agrícola con la de las ventas de productos agrícolas. Las dos categorías situadas por encima de 3000 dólares de ventas anuales abarcan sólo el $17 \%$ del número de explotaciones, pero cerca del $90 \%$ de la producción y una proporción por supuesto, aún mayor del monto total de ventas. Su grado de "mercantilización" se sitúa lógicamente por encima de la media nacional (incluyendo ejidos), que fue de $80 \%$ aproximadamente.

Nuevamente, la inclusión de las parcelas ejidales presenta grandes dificultades. En promedio, se colocarían por debajo de las empresas de 3 001-75 000 dólares y cerca del grado medio de comercialización de la producción a nivel nacional, con un $77 \%$. En efecto, el monto total de sus ventas de productos agrícolas se elevó a 4543 millones de pesos (unos 363 millones de dólares), aunque la producción

DISTRIBUCION DE LA PRODUCCIÓN Y GRADO DE COMERCIALIZACIÓN POR CATEGORIAS DE MONTO DE VENTAS DE PRODUCTOS AGRICOLAS (EN PORCENTAJES DEL TOTAL - "SECTOR PRIVA-

$$
\text { DO"-1960) }
$$

\begin{tabular}{ccccc}
\hline $\begin{array}{c}\text { Categorias (monto } \\
\text { de ventas anual } \\
\text { en dólares) }\end{array}$ & $\begin{array}{c}\text { Número } \\
\text { de explota- } \\
\text { ciones }\end{array}$ & $\begin{array}{c}\text { Producción } \\
\text { agricola }\end{array}$ & $\begin{array}{c}\text { Ventas del } \\
\text { año }\end{array}$ & $\begin{array}{c}\text { Ventas como\% } \\
\text { de la produc- } \\
\text { ción }\end{array}$ \\
\hline Más de 75000 & 1.5 & 56.5 & 60.4 & 91.0 \\
Sin ventas & 41.2 & 2.3 & - & - \\
Menos de 3000 & 41.6 & 8.4 & 6.6 & 67.5 \\
$3001-75000$ & 15.7 & 32.8 & 33.0 & 85.0 \\
Más de 75000 & 1.5 & 56.5 & 60.4 & 91.0 \\
$\quad$ & 100.0 & 100.0 & 100.0 & 84.0 \\
\hline
\end{tabular}

FUENTE: Elaboración propia sobre la base de censos. Véase Apéndice. total está probablemente subestimada en razón del consumo propio de los ejidatarios, del que puede omitirse una gran parte en las estadísticas.

\subsubsection{Productos característicos}

La constitución del "nuevo latifundio" como empresa capitalista moderna rodeada de un campesinado en buena parte semiproletario, da lugar a una distribución de funciones entre ambos sectores que se refleja en la composición real de la producción: en la empresa capitalista se concentran los cultivos más altamente comercializados y dcxportación, y en las explotaciones campesinas se concentran relativamente las producciones de subsistencia y algunas para el mercado interno.

El algodón, cultivo industrial y de exportación, y el trigo, proclucto en el que más efecto han producido las nuevas variedades introducidas, se cultivan en los últimos años en un $80 \%$ y en un $70 \%$, respectivamente, en tierras de regadío y tipifican el primer grupo. Junto con el maíz no pasaban de $1 / 4$ del consumo total de abonos en 1950, pero en 1962 ya sobrepasaban los 4/5. Para el trigo, la aplicación de abonos por hectárea se multiplicó por 104, y por tonelada obtenida por 49, entre esas dos fechas (ver Vargas Torres, op. cit. y Anuarios Estadísticos) y alcanzó $50 \mathrm{~kg}$. de nutrientes por has. y $35 \mathrm{~kg}$. por tonelada en 1962 (60 kg. y $100 \mathrm{~kg}$. para el algodón, respectivamente). Se ha llegado a fertilizar las $3 / 4$ partes de la superficie cosechada de estos dos cultivos.

El maíz híbrido constituye un ejemplo intermedio, correspondiendo en gran parte a empresas capitalistas y produciéndose aun para exportación. El maíz común y los frijoles (10\% en tierras de regadío) representan los elementos principales de la dieta común tradicional.

\subsection{Regiones características}

El desarrollo de la moderna empresa capitalista no ha sido uniforme geográficamente. Se han convertido en ámbito fundamental de este tipo de explotación las regiones septentrionales, sobre todo la llamada del Pacífico Norte ${ }^{24} \mathrm{y}$, también, la del Norte, ${ }^{25}$ mientras

${ }^{24}$ Comprende los siguientes estados: Baja California Sur, Baja California Norte, Nayarit, Sinaloa, Sonora.

${ }_{25}$ Comprende Coahuila, Chihuahua, Durango, Nuevo León, San Luis Potosí, Tamaulipas y Zacatecas. 
que la vieja región del Centro $^{26}$ constituye la zona campesina por excelencia. Esta última fue uno de los ámbitos fundamentales de la reforma agraria; aquéllas fueron abiertas a la producción en buena parte por la "reforma agrícola".

Aunque el Pacífico Norte tenía en 1960 menos de $1 / 3$ de la tierra de regadío de todo el país, estas extensiones representaban allí casi el $5 \%$ de la superficie total de la región y más del $44 \%$ de la tierra de labor (en todo el pais: $2.1 \%$ y $14.9 \%$, respectivamente). Por ejemplo: un solo distrito de regadío —el del Valle de Santo Domingo- absorbe el $80 \%$ de la producción agrícola de un estado entero (Baja California Sur) con sus cultivos de trigo, algodón, cártamo y alfalfa (la ganadería tiene importancia) (Comercio Exterior, octubre de 1968). La producción de algodón representaba en 1960 más del $43 \%$ del total nacional en moneda, y la de trigo cl $16 \%$.

Los índices de mecanización de las tareas agrícolas, especialmente ios referentes a las máquinas más modernas (tractores), alcanzan su máximo en esta región. Lo mismo ocurre con los índices de importancia del trabajo asalariado dentro del total.

En el Centro, la tierra de regadío alcanza el porcentaje más alto del país referido a la superficie total, pero no representa más que el $15.3 \%$ de la tierra de labor. Allí se encuentra buena parte de la producción de subsistencia principal: $40.7 \%$ del total del maíz, y un $28 \%$ del frijol. Los índices de mecanización son bajos así como el peso relativo de las relaciones salariales.

Es en las zonas de próspera agricultura practicada sobre bases capitalistas, y que ejemplifican las regiones septentrionales, donde se reinvierte una parte de los beneficios de cierta burguesía comercial monopolista que distribuye los bienes y servicios y acopia la producción campesina en la mayor parte del país, muy ligada a los grupos financieros y burocráticos. Varios autores, al describir la etapa que se abre en la década de 1940, aseveran que "las mejores tierras, las de riego, y los otros recursos: capital, fuerza de trabajo, crédito e insumos físicos empiezan a concentrarse en determinadas regiones y en manos de unos cuantos propietarios". ${ }^{27} \mathrm{Y}$ agregan: "... ese crecimiento abre las puertas al capital extranjero, que inicia el proceso de control de la agricultura nacional".

26 Comprende Aguascalientes, Distrito Federal (ciudad de México) y alrededores), Guanajuato, Hidalgo, Jalisco, México, Michoacán, Morelos, Puebla, Querétaro y Tlaxcala.

27 STAVENHAGEN y otros, op. cit.
Lógicamente, no gozan de amplia difusión los datos referentes a esta nueva expansión de las inversiones extranjeras. Ni puede tomarse como índice de ella la cantidad de tierras pertenecientes a empresas cxtranjeras - menos aún, la cantidad de tierras que figuran como tales. Testimonios cualitativos diversos indican que las industrias de la alimentación y otras utilizadoras de productos agrícolas son uno de los campos principales de la inversión norteamericana en México. y ésta es una corriente de control de la agricultura. El control de tierras por parte de grandes empresas industriales se da a menudo bajo formas ilegales, por lo que no puede registrarse en las estadísticas. Y no es la cantidad de tierra, en todo caso, la que da la verdadera importancia de la magnitud económica de los establecimienios agrícolas. ${ }^{28}$

\section{INDIGES DE MEGANIZAGIÓN DE LAS TAREAS AGRICOLAS} POR REGIONES

(Como porcentajes del total nacional, 1960)

\begin{tabular}{lcccc}
\hline \multicolumn{1}{c}{ Concepto } & México & $\begin{array}{c}\text { Pacífico } \\
\text { Norte }\end{array}$ & Norte & $\begin{array}{c}\text { Pacífico Sur } \\
\text { Golfo y Centro }\end{array}$ \\
\hline $\begin{array}{l}\text { Superficie cultivada } \\
\begin{array}{l}\text { Sup. cultivada con } \\
\text { tracción mecánica } \\
\text { como \% de la sup. }\end{array}\end{array}$ & 100.0 & 11.0 & 26.3 & 62.7 \\
$\begin{array}{l}\text { cultivada total } \\
\begin{array}{l}\text { Valor de la maqui- } \\
\text { naria agríc. y }\end{array}\end{array}$ & 8.3 & 25.3 & 13.2 & 3.1 \\
$\begin{array}{l}\text { vehículos } \\
\text { (Dentro de él: }\end{array}$ & 100.0 & 24.0 & 39.5 & 36.5 \\
$\begin{array}{l}\text {-Arados de madera } \\
\text {-Tractores }\end{array}$ & $(100.0)$ & $(3.4)$ & $(18.1)$ & $(78.5)$ \\
\hline
\end{tabular}

Fuente: IV Censos Agricola-ganadera y Ejidal 1960. Resumen General.

28 "Un pequeño grupo de capitalistas controla el grueso de las principales cosechas de exportación pero no posee una proporción grande de tierras en México; la reforma agraria terminó con ese problema particular. Sin embargo, en un medio moderno, su acceso a los recursos del gobierno para el desarrollo agrícola - inclusive los servicios de extensión agrícola, facilidades crediticias y capital físico fijo- es más importante en la determinación del ingreso. No puede ser casual que muchos de estos capitalistas formen parte del establecimiento agrícola corporativo, estrechamente ligado a los intereses extranjeros." (DAVID BARKIN, "La persistencia de la pobreza en México. Un análisis económico estructural", en Desarrollo Económico, No. 38, Julio-septiembre 1970 . 
Sobre la presencia de capitales norteamericanos en la agricultura misma decía una fuente norteamericana hace más de veinte años: "Los EUA son, con mucho, la principal fuente de capital extranjero invertido en la agricultura mexicana. La mayor parte de las inversiones norteamericanas en la agricultura están colocadas en grandes explotaciones, muchas de ellas de más de mil has. Hay también cantidades considerables de capitales norteamericanos en la producción y comercialización de verduras de invierno y hortalizas '(truck crops)."29

Y, a falta de datos más precisos, podemos recurrir a otra opinión norteamericana. Ronald Hilton decía en un coloquio internacional en 1967: "Se ha citado el caso del noroeste de México (Pacífico Norte), se ha dicho que es la región donde la agricultura es más floreciente... (pero) es justamente en esa región -que no se me acuse de imperialismo norteamericano- ...donde las inversiones norteamericanas en la agricultura son muy importantes aunque disimuladas, donde la influencia de la agricultura a través de la frontera californiana es muy fuerte. De tal modo que no se trata de un fenómeno puramente mexicano, sino de un fenómeno que se produce en México bajo la influencia - benéfica, a mi modo de ver, en este caso- de los EUA." 30

\subsection{Intento de sintesis por categorías de explotaciones}

Para obtener de la información estadística disponible (censos). los cuadros sintéticos que se insertan, fue necesario sentar algunas hipótesis, fuertes en ciertos casos pero, al parecer, inevitables, que se detallan en el Apéndice.

De entre los intentos similares a éste en el sentido de la elaboración de una presentación sintética, pueden mencionarse dos. Rodolfo Stavenhagen ha construido un cuadro que correlaciona tentativamente la distribución de la población económicamente activa en la agricultura con la distribución de la tierra de cultivo, a través de los censos de 1950 y de 1960 . Sin embargo, presenta los ejidos como una categoría compacta y aparte y no emprende un intento de distribución de los asalariados por categorías de explotaciones. ${ }^{31}$

${ }_{29}$ "Agricultural, Pastoral and Forest Industries in Mexico", U. S. Tariff Commission, Washington 1948, p. 24

30 Les problemes Agraires des Ameriques Latines, cNrs, Paris 1967 (debates).

31 RODOlfo Stavenhagen, op. cit., p. 485.
DISTRIBUCION ESTIMATIVA DE LOS RECURSOS PRODUGTIVOS $Y$ DE LA PRODUCGION AGRICOLA POR CATEGORIAS DE EXPLOTAGIONES, 1960

(En porcentajes del total)

\begin{tabular}{|c|c|c|c|c|c|c|}
\hline Categoriast & $\begin{array}{l}\text { Número } \\
\text { de explo- } \\
\text { taciones }\end{array}$ & $\begin{array}{c}\text { Fuerza de } \\
\text { trabajo }\end{array}$ & $\begin{array}{l}\text { Tierra } \\
\text { culti- } \\
\text { vable }\end{array}$ & $\begin{array}{l}\text { Tierra } \\
\text { de re- } \\
\text { gadio }\end{array}$ & $\begin{array}{l}\text { Valor de } \\
\text { la maqui- } \\
\text { naria, im- } \\
\text { plementos } \\
\text { agricolas } \\
\text { y vehiculos }\end{array}$ & $\begin{array}{l}\text { Valor } \\
\text { de la } \\
\text { producción } \\
\text { agrícola }\end{array}$ \\
\hline \multirow{4}{*}{$\begin{array}{l}\text { Minifundios } \\
\text { Tamaño fa- } \\
\text { miliar } \\
\text { Empresas ca- } \\
\text { pitalistas me- } \\
\text { dianas } \\
\text { Empresas ca- } \\
\text { pitalistas } \\
\text { grandes }\end{array}$} & 58.8 & 44.7 & 11.7 & 9.2 & 6.3 & 11.0 \\
\hline & 38.5 & 41.3 & 47.2 & 38.4 & 36.6 & 42.9 \\
\hline & 2.5 & 9.0 & 17.3 & 32.2 & 36.6 & 23.1 \\
\hline & 0.2 & 5.0 & 23.8 & 20.2 & 20.5 & 23.0 \\
\hline Total & 100.0 & 100.0 & 100.0 & 100.0 & 100.0 & 100.0 \\
\hline
\end{tabular}

1 Se definen en términos de tierra de cultivo por los siguientes límites: explotaciones del "sector privado" hasta 5 has. y ejidales hasta 4 has; 5-25 has. y más de 4 has., respectivamente; 25-200 has.; más de 200 has. Se excluyeron las explotaciones carentes de tierra cultivable. Se considera como una unidad la parcela de cada ejidatario, no cada ejido.

2 Se tomó el número total de personas que trabajaron durante el año, sin distinción de sexo ni edad. Las estadísticas no indican el número de jornadas trabajados por cada uno, por lo que no pudo tenérselo en cuenta tampoco.

FUENTE: Elaboración propia sobre los IV Censos Agricola-ganadero y Ejidal 1960. Resumen general.

Solomón Eckstein, en un cuadro más similar al que se presenta aquí, pone de manifiesto esencialmente que, en un extremo, las explotaciones que llama de "infrasubsistencia" (más de la mitad en número) disponen del $13 \%$ de la tierra cultivable, de menos del $1.5 \%$ de las máquinas agrícolas (en valor) y de una proporción despreciable de la tierra irrigada mientras que, en el extremo opuesto, las explotaciones "multifamiliares grandes", $.5 \%$ solamente del total en número, tienen una participación mucho mayor en la tierra de cul, 
tivo, y sobre todo, en la de regadío $(37.6 \%)$ y en el parque de maquinaria agrícola $(43.7 \%)$. El valor de la producción resulta distribuido gruesamente en forma proporcional a los recursos productivos materiales en su conjunto (Comercio Exterior, marzo de 1969, ensayo bibliográfico de S. Reyes Osorio). La deficiencia principal que presenta este cuadro, en mi opinión, es que muestra la distribución de los recursos materiales pero no la de la fuerza de trabajo.

Puede constatarse fácilmente en el cuadro preinserto la desigualdad que reina en la distribución de los recursos, particularmente en los rubros más relacionados con la productividad potencial del trabajo (tierra de regadío, maquinaria agrícola). Si se comparan los minifundios con las empresas capitalistas "medianas", se ve que los primeros pesan menos en la distribución de la tierra de riego que en la de la tierra de labor en general y menos aún en la de la maquinaria agrícola, mientras que en las segundas es al revés.

En cambio, al ir considerando categorías de explotaciones cada vez más grandes, la fuerza de trabajo va perdiendo importancia en porcentaje, dado que las unidades más pequeñas están basadas en extensiones chicas y superpobladas, mientras que las empresas capitalistas utilizan fuerza de trabajo tanto menos numerosa proporcionalmente y tanto mejor equipada en recursos materiales, cuanto mayor su extensión.

Puede mencionarse que, en la región del Pacífico Norte, las unidades capitalistas y de tamaño familiar son relativamente numerosas y ocupan una parte considerable de la fuerza de trabajo, mientras los recursos materiales están relativamente más concentrados en manos de los empresarios capitalistas. En la región campesina por excelencia - $\mathrm{l}$ Centro-, en cambio, la superpoblación relativa impone el cultivo muy intensivo -específicamente intensivo en mano de obra-a los numerosos minifundistas. "Hay zonas en el Centro de México, allí donde la densidad demográfica es más alta, en las que la atomización de las explotaciones alcanza tal grado que la superficie de las explotaciones se mide por yardas o por surcos (furrows) más bien que por hectáreas." ${ }^{\prime 32}$ En el otro extremo de la distribución, las grandes explotaciones son muy pocas.

Para tratar la productividad y el rendimiento de los factores materiales se han tratado de otro modo los mismos datos estimativos del cuadro anterior. La mitad izquierda del nuevo cuadro resultante encierra índices de "intensidad de explotación" referentes a los "factores", mientras que a la derecha están indicados la productividad del

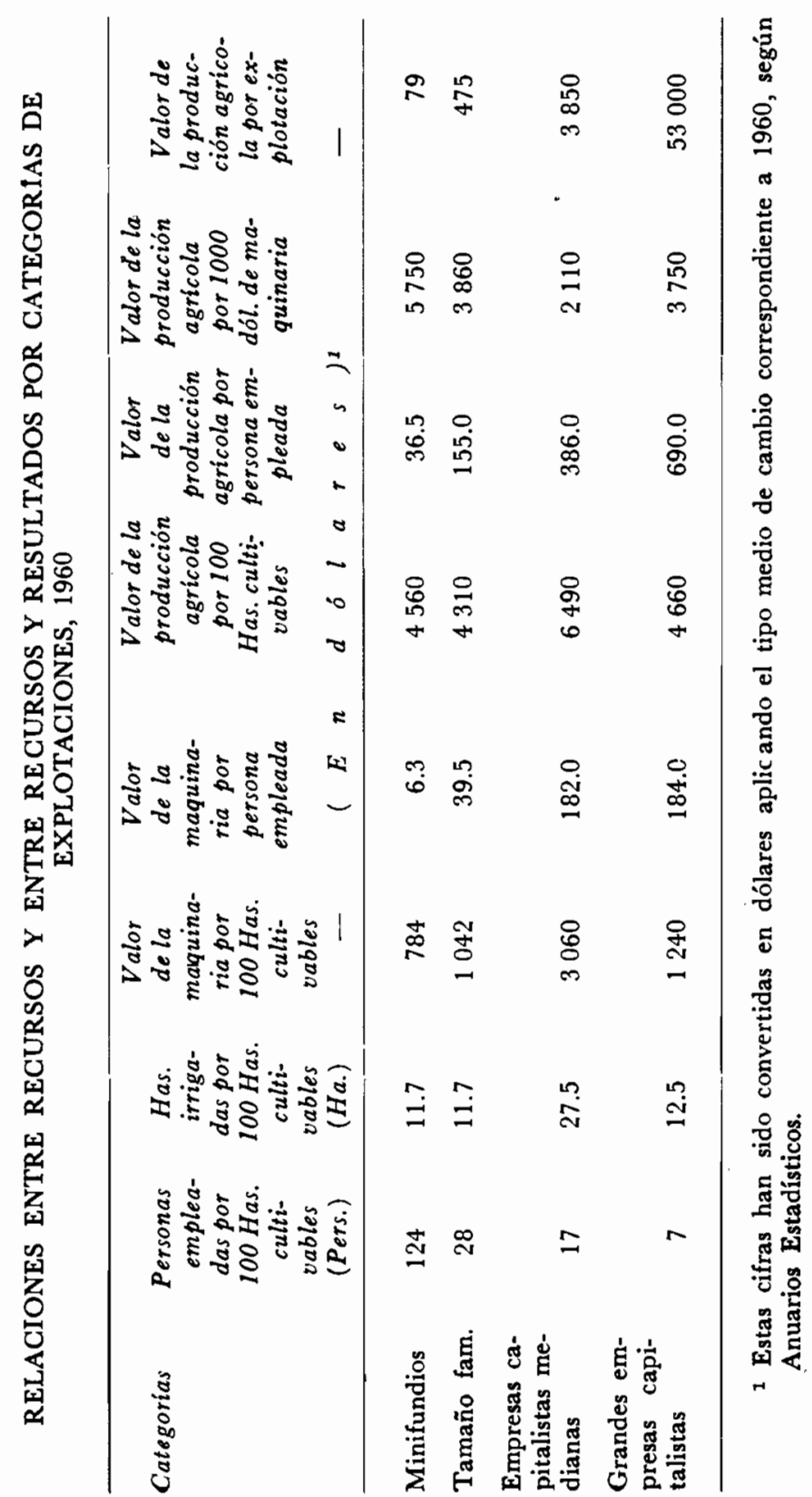

\footnotetext{
32 STAVEnhagen, op. cit.
} 
trabajo y el rendimiento de cada uno de los factores materiales, para cada categoría de explotaciones.

En la categoría de los minifundios se observa el carácter de "recurso abundante" que reviste la fuerza de trabajo (hacinamiento), mientras que el bajo nivel de tecnificación se expresa en el valor de la maquinaria por ha. y, más claramente aún, por persona. La baja productividad del trabajo impide la acumulación, con lo que la productividad sigue siendo baja. En el nivel de las explotaciones "de tamaño familiar" puede hablarse de una moderada capacidad de acumulación.

Las relaciones presentadas en el cuadro explican que en las empresas capitalistas medianas aparezca ya un índice de productividad muy superior, el máximo rendimiento por ha. y el más bajo por unidad de valor de la maquinaria. A partir de este nivel ya no hay verdaderos recursos escasos, en virtud de la capacidad financiera que aparece aquí.

En las grandes explotaciones capitalistas el rendimiento por ha. resulta comparable al de los minifundios. Frente a la intensidad de mano de obra de éstos, aparece en aquéllas la calificación de la fuerza de trabajo y la mayor dotación técnica, cualitativa y cuantitativa. Los rendimientos globales, por lo demás, se consideran en valor, y a esta categoría corresponden cultivos altamente rendidores difícilmente accesibles a los pequeños agricultores.

El rendimiento de la maquinaria es superior al que se alcanzaba en las empresas medianas, lo que ha de estar en relación con la posibilidad de utilizarla más plenamente sobre superficies mayores.

Nuevamente, aquí no hay verdaderos recursos escasos. Las opciones empresariales resultan libres en función de estimulantes de mercado, todos los factores pueden obtenerse en las cantidades más rentables. Un autor decía hace unos años al tratar las grandes explotaciones de la parte septentrional de México que "la prosperidad y la mecanización, al parecer, no resultan posibles sino en unidades de esta magnitud".33

\section{CONCLUSIÓN}

La revolución mexicana expresó reivindicaciones heterogéneas en un país dependiente, en un periodo de rápida expansión de la inversión extranjera y de alto grado de monopolización de la propiedad

\footnotetext{
33 HOWARD GLINE, Op. cit., p. 485 ,
}

territorial. En la esfera agraria, más que en cualquier otra, se manifestaron estas contradicciones.

Las masas de campesinos en armas constituyeron la fuerza motriz principal en la lucha armada, sin que sus líderes directos pudiesen acaudillar el movimiento en su conjunto, limitados por la propia ideología sectorial, específicamente agrarista, que los animaba. La coexistencia de los modelos de la pequeña propiedad y del ejido en la reforma agraria, en ausencia de un esquema revolucionario para la sociedad en su conjunto, tuvo que resolverse progresivamente a favor de la primera — cada vez menos pequeña_, en una modernización de la agricultura sobre bases capitalistas. La reforma agraria fue justamente una auténtica reforma, no la utópica "revolución agraria" en el seno de una sociedad cuyo marco global no se alteraba. Sentó las bases de una relatva paz social temporal mediante el reparto de una porción de los latifundios, a la vez que contribuyó a que "el México socialista se aproximara a ser el país latinoameircano que mejor había sabido adaptarse al clima del capitalismo de la segunda mitad del siglo $\mathrm{xx}$ ". ${ }^{34}$

\section{APENDICE}

\subsection{Metodología para la elaboración de los cuadros sintéticos}

Las categorías básicas de la información estadística mexicana son: 1) ejidos; 2) explotaciones privadas menores de 5 has. de superficie; 3) explotaciones privadas mayores de 5 has. de superficie. Tanto la categoría que comprende las explotaciones de los ejidatarios como, en medida mucho mayor aún, la de las explotaciones del "sector privado" que superan 5 has. de superficie, engloban fenómenos heterogéneos. Se consideró que no permitían elaborar directamente presentaciones estadísticas referentes a la distribución de recursos y resultados productivos correlacionados por categorías de explotaciones agrícolas en forma significativa.

La información censal incluye datos abiertos por categorías más diferenciadas (sobre todo el caso del llamado "sector privado"). Sin embargo, la distribución de cada variable viene dispuesta por categorías definidas en términos de la misma variable (superficie de labor distribuida por categorías de superficie de labor por explotación; va-

34 TULIO HALTERIN, Historia contemporánea de América Latina, Madrid, 1969 , 
lor de la maquinaria agrícola, etcétera, por categorías de valor de la maquinaria agrícola, etcétera, por explotación, y así sucesivamente), lo que hace imposible correlacionar las diversas variables, en forma directa, para cada categoría de explotaciones.

Así pues, se definieron las categorías en términos de tierra de labor por explotación como se indica en nota al pie del primer cuadro de síntesis. Para distribuir el conjunto de las variables entre estas categorías de explotaciones, hubo que efectuar supuestos o hipótesis sin los cuales ello hubiera sido imposible, aunque en algunos casos puedan implicar desvíos de alguna importancia:

a) Ejidos:

- Se supuso una media de 2 has. de labor para las parcelas de menos de 4 has. de labor, lo que arroja una media, al parecer plausible (por residuo) de 10.3 ha. de labor para las parcelas de más de 4 has. de este tipo de tierra.

- Se distribuyó la fuerza de trabajo familiar proporcionalmente al número de explotaciones (los datos no permiten aplicar el mismo criterio que en el "sector privado") que integran cada una de las dos categorías, y el total de la fuerza de trabajo asalariada se imputó a las parcelas ejidales clasificadas como de tamaño "familiar" (más de 4 has. de labor).

- Ya que ningún otro criterio arrojaba resultados verosímiles, la tierra de regadío, el valor de la maquinaria, y el valor de la producción agrícola se atribuyeron en proporción a la superficie de labor.

b) "Sector privado": explotaciones de más de 5 has. de superficie:

- El total de la fuerza de trabajo familiar se imputó a las explotaciones definidas como de tamaño "familiar", y el total de la fuerza de trabajo asalariada a las empresas capitalistas. No parece excesivamente arriesgado suponer, como se hizo, que la fuerza de trabajo efectivamente comprada (asalariada) en las explotaciones predominantemente campesinas, se compense aproximadamente con la fuerza de trabajo familiar que, inversamente, emplean las empresas capitalistas.

- Para las explotaciones campesinas (minifundio y tamaño familiar) se supuso una distribución de la fuerza de trabajo conjunta asi obtenida, proporcional a la superficie de labor de cada una de ellas. Esto puede implicar cierta subestimación de la fuerza de trabajo empleada en los minifundios y sobrevaluación de ella en las

\subsection{Versiones regionales del primer cuadro sintético}

DISTRIBUCION ESTIMATIVA DE LOS RECURSOS PRODUCTIVOS

Y DE LA PRODUCCION AGR ICOLA POR CATEGORIAS, EN PORCENTAJES DEL TOTAL, 1960

\begin{tabular}{|c|c|c|c|c|c|c|}
\hline Categorias & $\begin{array}{l}\text { Número } \\
\text { de ex- } \\
\text { plota- } \\
\text { ciones }\end{array}$ & $\begin{array}{c}\text { Fuerza } \\
\text { de tra- } \\
\text { bajo }\end{array}$ & $\begin{array}{l}\text { Tierra } \\
\text { culti- } \\
\text { vable }\end{array}$ & $\begin{array}{l}\text { Tierra } \\
\text { de re- } \\
\text { gadio }\end{array}$ & $\begin{array}{l}\text { Valor } \\
\text { de la } \\
\text { maqui- } \\
\text { naria, } \\
\text { etc. }\end{array}$ & $\begin{array}{l}\text { Valor } \\
\text { de la } \\
\text { producción } \\
\text { agrícola }\end{array}$ \\
\hline
\end{tabular}

A) Región del Pacifico Norte

$\begin{array}{lrrrrrr}\text { Minifundios } & 20.8 & 11.5 & 2.4 & 2.2 & 1.2 & 2.1 \\ \begin{array}{l}\text { Tamaño familiar } \\ \text { Empresas capi- }\end{array} & 71.3 & 61.1 & 49.6 & 32.1 & 26.5 & 38.2 \\ \begin{array}{l}\text { talistas media- } \\ \text { nas }\end{array} & 7.2 & 20.4 & 24.5 & 39.6 & 43.0 & 31.5 \\ \begin{array}{l}\text { Grandes empre- } \\ \text { sas capitalistas }\end{array} & 0.7 & 7.0 & 23.5 & 26.1 & 29.3 & 28.2 \\ \quad \text { TotaL } & 100.0 & 100.0 & 100.0 & 100.0 & 100.0 & 100.0\end{array}$

B) Región del Centro

\begin{tabular}{lrrrrrr} 
Minifundios & 71.4 & 59.7 & 22.5 & 20.4 & 15.8 & 21.0 \\
$\begin{array}{l}\text { Tamaño familiar } \\
\begin{array}{l}\text { Empresas capi- } \\
\text { talistas media- }\end{array}\end{array}$ & 27.0 & 31.4 & 50.0 & 45.1 & 38.5 & 43.1 \\
$\begin{array}{l}\text { nas } \\
\begin{array}{l}\text { Grandes empre- } \\
\text { sas capitalistas }\end{array}\end{array}$ & 1.5 & 5.6 & 17.9 & 20.6 & 31.2 & 21.8 \\
$\quad 0.1$ & 3.3 & 9.6 & 13.9 & 14.5 & 14.1 \\
$\quad$ TotaL & 100.0 & 100.0 & 100.0 & 100.0 & 100.0 & 100.0 \\
\hline
\end{tabular}

FUENTE: Elaboración propia sobre la base de los IV Censos Agricola-ganadero y Ejidal 1960. Resumen general.

unidades de trabajo familiar. También es posible, sin embargo, que la fuerza de trabajo campesina se redistribuya en cierta medida a través de lazos de parentesco y otros, tendiendo a nivelar el grado de hacinamiento.

- Para distribuir la fuerza de trabajo asalariada entre las dos categorías de empresas capitalistas, se supuso un media de 10 personas para las medianas lo que arroja - por residuo- una media de 77 personas para las grandes en escala nacional, lo que no parece absurdo. 
- Para distribuir las demás variables (tierra de regadío, valor de las máquinas, valor de la producción, monto de ventas) se supuso que las explotaciones se distribuían, según estas variables, más o menos en el mismo orden que según la tierra de labor. Naturalmente, se trató de hacer coincidir al máximo los efectivos de las categorias en las diversas distribuciones.

c) "Sector privado": explotaciones de menos de 5 has.:

Es éste el único grupo de la clasificación censal que no requirió la adopción de ningún supuesto, ya que entra en su integridad en el grupo definido como de los minifundios. 